\title{
Discrete Levels and Limits of Free Choice.
}

What turns individuals, groups and organizations into a 'human machinery'?

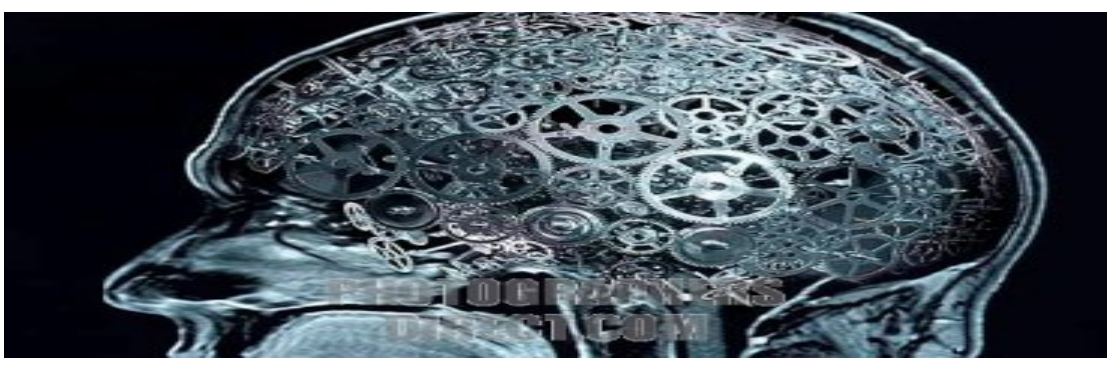

(When the accumulation of wealth is no longer of high social importance, there will be great changes in the code of morals...The love of money as a possession... will be recognized for what it is, a somewhat disgusting morbidity, one of those semi-criminal, semi-pathological prospensities which one hands over with a shudder to the specialists in mental disease...This means that the economic problem is not-if we look into the future- the permanent problem of the human race).

JM. Keynes.”Economic Possibilties for our Grandchildren” (1933).

(in: Essays in Persuasion.London: Macmillan).

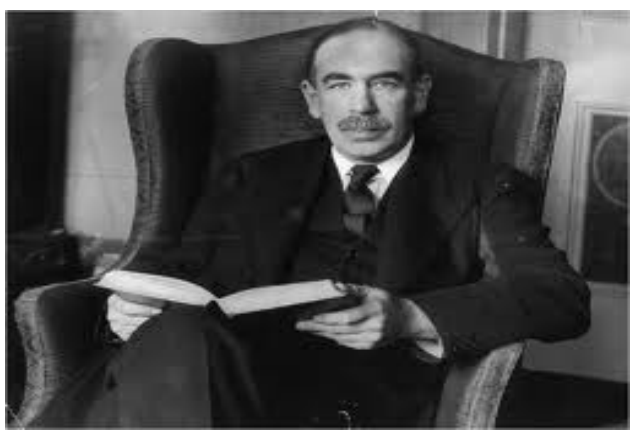

Independent research scientist, O\#0 van Nieuwenhuijze (MS, MD), asked me to explore the question of discrete levels and limits of free choice in more detail and the following elaborations may serve for a 
more profound interview, concerning this very permanent problem of the human race.

Deep social psychology has a more hiddeneffect on our souls than we might expect; our life is a pilgrimage of dreams and realizations.Among the social science community, the psychological school of economics is very well aware about eco-logical inter-action of labor, work, health and values. In this view, spontaneous and decentral self-organization is regarded as the core principle in nature and humanity. The physio-logical acts of labor, the psycho-logical acts of work, the value decisions in economic life and mental/bodily health are seen as an integral working body of vital stress on our stimulus-response organism (which is not a mechanism). This organization principle or natural law sees nothing meta-physical in the living interplay of conscious, unconscious and subconscious reactions of the human organism as individual and/or collective unit, e.g. all human hearts may have deeper emotional reasons that rational reasoning alone cannot detect. This observation leads to the iceberg metaphor of human social organization, which sees different levels of awareness in human action, according to distinct levels of brain activation. The human brain is a non-stop laboring powerhouse that employs gradual stages of conscious realizations, unconscious routines/habits und subconscious dreams; the crucial question is about the relative proportions or percentages that these organic activities make up, allowing also for personal differences. A good social scientist must not only be a methodical maths expert and learned in applied natural science, but also a research pioneer into the human mind.

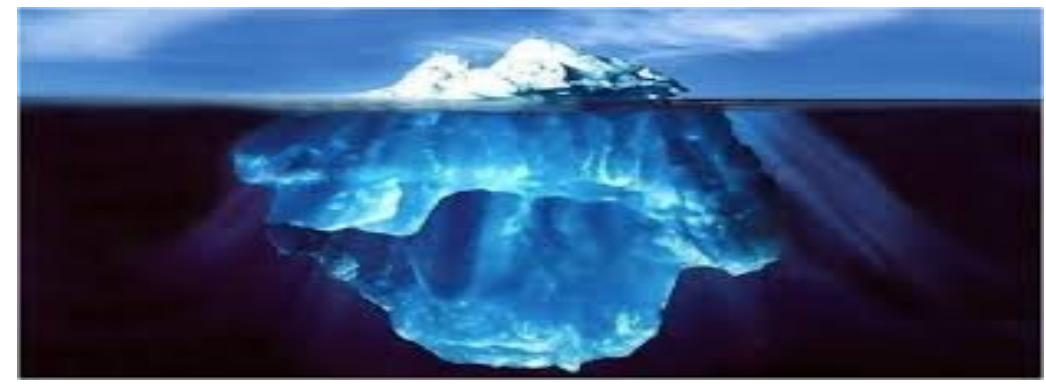

Our egos demand freedom, the freedom of choice; concepts of free choice are cognitive products of human consciousness. However, there is no empirical evidence for free choice, it remains an assertion, a conjecture or an invention. The great task of our life is to choose , 
among multiple opportunities and demands, but it is essentially difficult to be aware of the value matrix of our choice. We are persistently engaged with construction principles of reality ( natural law/physical constraints), exposed to contrary ideas and ideals, challenged by opposing belief systems and searching for the improvement of life. Whole societies have made profound shifts, from slavery to more liberty, based on a significant number of individuals by developing their minds. Consequently, we can learn new ideas and perspectives, but only in the physical framework of our historical experience and genetic capacity. Human behavior operates on two discrete levels: genetics and learning; much of human behavior is scientifically a result of our physical inheritance, forgotten life events and unknowable genetic dospositions.

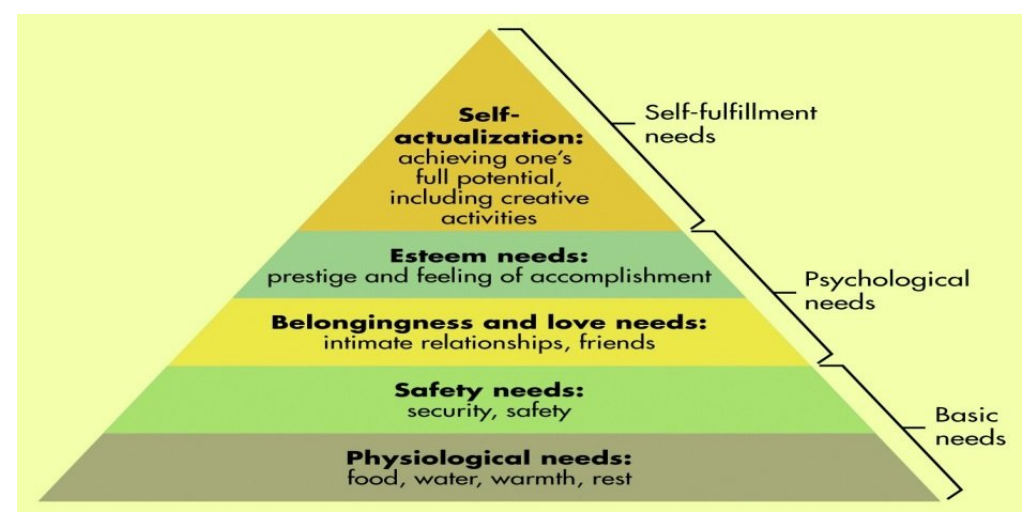

The physio-logical level of labor and genetics is very distinct from the psycho-logical level of work and learning. The former works more like a 'bio-logical clock' and can be served wisely by adaptive beavioral decisions (e.g. preventive health care; basic life skills), the later resembles a 'mental clock' that can be set or reset by intelligent programming (e.g. practical reflexion; ethical awareness). Consequently, the spiritual sphere of the human freedom of choice is a result of advanced ethical systems of morality for value decisions (e.g. every single purchase act/payment is a value decision, i.e. it is not possible to think and act ethically without considering the economic effect on the natural and human environment). From this viewpoint, three decisive monopolies have to be considered: 1 ) the monopoly or privilege on natural resources (e.g. land value); 2) the monopoly or privilege on monetary resources (e.g. capital value), 3) the monopoly or privilege on taxation (e.g. income and asset value). It is not possible to foresee or anticipate social systems evolution, but it is more than likely that the question of redefining human rights for our technological stage will gain mass momentum. However, let us 
be cautious: great social conflicts, revolutions and wars have not lead to change, but too rapid change has always lead to the above mentioned social upheavals. Consequently, the human degrees of freedom of choice can only be elaborated by gradual radical reforms towards a de-central social market economics. The most important societal function for such a psycho-mental shift is: management or converting resources into values.

\section{seek sense Share}

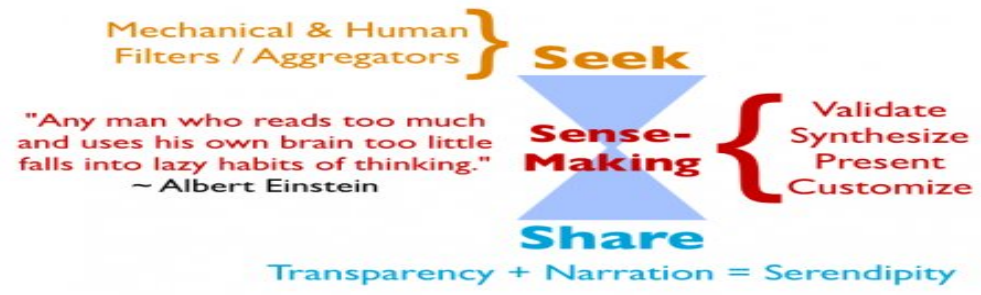

Cybernetics, systems science and information theory are pointing

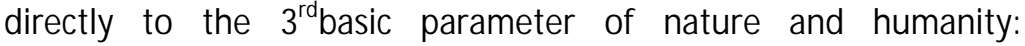
information. It is impossible to reduce the phenomena of the physical world into two elementary units: energy and matter. Life is informed energy and matter; all systems, natural or artificial, follow certain regular laws of operation (information flow). The mental root of the current economic crisis is the management reductionism of profit maximation, shareholder-focus and corporate risk, but only variety can communicate with variety and is able to communicate with entrepreneurial complexity, i.e. management reductionism is the direct road to collapse and crisis, destroys the productivity and prosperity of firms, leads to systemic instability and wealth as values are being ultimately dumped. Therefore, it is impossible to disconnect mental health, economic action and bodily health; on the contrary, there is an underlying sequential order of causes in human behavior. The global financial crisis is a perfect example of mental errors and psychological mistakes, despite all monetary forensics and big data science; it is an exact showcase of the deeper layers of social psychology in mass motion. This pseudo-mathematical alchemy of financial money-pulation and money-pollution has already got its systems response from the biophysical limits of the production economy, i.e. economic instability/unsustainability is the direct feedback or effect of this false models of thought (e.g. emitting monetary value that does not exist in the real economy). 


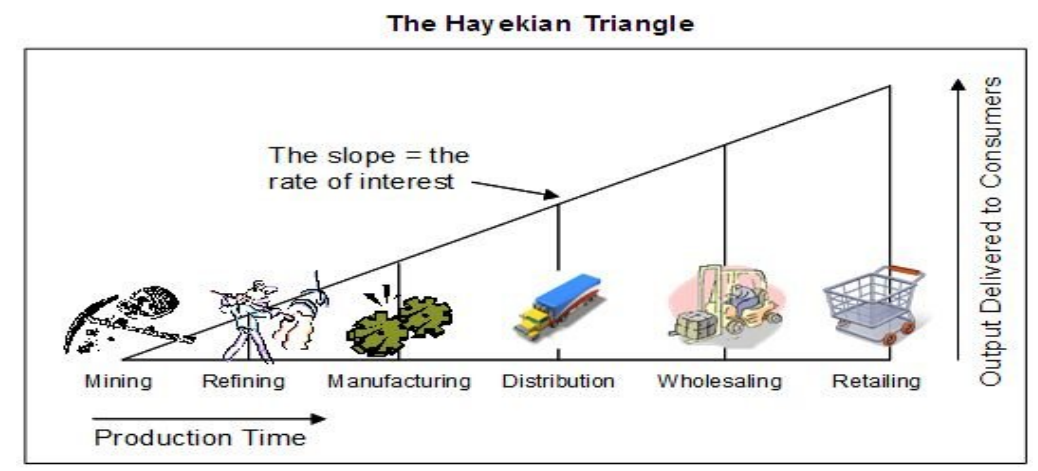

According to ancient rabbinic wisdom, every-body is being guided by the internal state of mind, i.e. by the permanent chain of thoughts that is transmitted organically in the temporal period of the twinkling of an eye. The gateway to sanity is mental health, that is to be extremely cautious of mind pollution which contaminates our heartbrain-hand sequence of acticity. The real-world realm of freedom of choice for human decisions are the ethical systems of morality that evolved in small-scale social groups in the long-term course ('curse') of the historical experience: all empircal facts document that linguistics, genetics and anthropological archeology are very densely inter-connected, in territorial or geophysical terms. However, there exists actually no ethical system of morality that fits global or largescale human organization, despite all religious claims of supercession or superiority; therefore, it is necessary to re-search or look beyond the geo-socio-biology of ethnic systems evolution in ethical codes. An observer from the moon would immediately recognize that global human organization is driven by 'competing economic gangs' that speculate for more 'territory', i.e. barbaric relicts have survived into the electronic age or as Israeli scientist Y.Bauer puts it: 'technically competent barbarians'. It is all about emotional, cognitive and methodical awareness, actually the practical application of the Golden Rule; all manipulation of free choice is based on the fear of the individual personality to act by applied reason, thereby delegating the authority or agency of decision-making to other functional levels of hierarchy. 


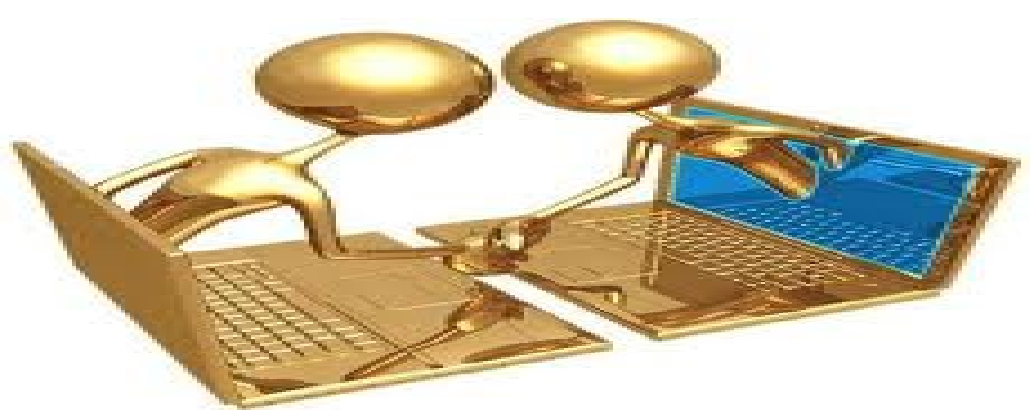

The social realization of self-organization is, first and foremost, a deep psychological barrier that is rooted in human nature; the origin of this fear is inherited from the animal kingdom where competition rules over co-operation (although it exits to some extent). The contemporary religion of money, an Ersatz omnipotence link for an all powerful deity, is exactly driven by this existential fear insearch of 'security', i.e. many monetary phenomena can be interpreted as a expectational rationalization of irrational fears, employing high speed computing and hereby accelerating and economizing the social dynamics of mass psycho-pathology. As mentioned before, it is impossible to disconnect mental health, economic decisions and physical sanity, because the underlying soft program are value decisions or e-valuations. The psychological school of economics, in application with moral philosophy and quantum physics, can precisely describe the retro-causal effect chain of false value decisions, that are informed by irrational fears in mass motion. Without delving too much into this vital topic, it can be surely assumed that a causal relationship between the human psyche and monetary affairs exists to a high socio-economic extent. Consequently, monetary agency has to be overthaught, objectified and rectified as the human psyche will remain the same in all places and times. Finally, it should be clarified again that these permanent false models of thought and value decisions 'create' unbearable and insane 'human machinery', being more powerful than any temporary evil intention.

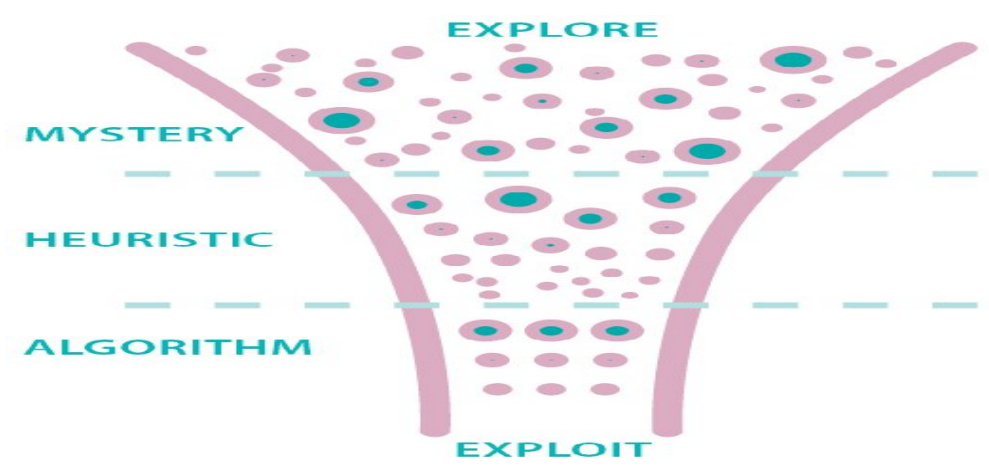


Suggested readings:

Azam I.2005. Moral Values Education. Islamabad: PFI.

Arendt H.1989. The Human Condition.Chicago: UP.

Fromm E.1941. Escape from Freedom.NY: Farrar/Rinehart.

Huerta de Soto J.2009. Theory of Dynamic Efficiency.NY: Routledge.

Ternyik S.1989. Social Learning Processes.Frankfurt: R.Fischer.

www.carl-jung.net

$\underline{\text { www.fromm-gesellschaft.eu }}$

www.henrygeorgeschool.org

www.norberteliasfoundation.nl

www.wilhelmreichtrust.org 